Cite this: J. Mater. Chem. B, 2014, 2 , 2168

Received 7th January 2014 Accepted 6th February 2014

DOI: $10.1039 / c 4 t b 00037 d$

www.rsc.org/MaterialsB

\section{Noncovalent functionalization of mesoporous silica nanoparticles with amphiphilic peptides $\uparrow$}

\author{
Melis Sardan, t $^{\mathrm{ab}}$ Adem Yildirim, *ab $^{\text {ab }}$ Didem Mumcuoglu, ab Ayse B. Tekinay ${ }^{\star a b}$ \\ and Mustafa O. Guler*ab
}

\begin{abstract}
The surface of mesoporous silica nanoparticles (MSNs) has been modified for enhancing their cellular uptake, cell targeting, bioimaging, and controlled drug release. For this purpose, covalent anchorage on the silica surface was predominantly exploited with a wide range of bioactive molecules. Here, we describe a facile self-assembly method to prepare a hybrid peptide silica system composed of octylmodified mesoporous silica nanoparticles (MSNs) and peptide amphiphiles (PAs). The hydrophobic organosilane surface of mesoporous silica was coated with amphiphilic peptide molecules. The peptide functionalized particles exhibited good cyto-compatibility with vascular smooth muscle and vascular endothelial cells. The peptide coating also improved the cellular uptake of particles up to 6.3 fold, which is promising for the development of highly efficient MSN based theranostic agents.
\end{abstract}

\section{Introduction}

Mesoporous silica nanoparticles (MSNs) have high specific surface area, large pore volume, controlled particle size and morphology, and low inherent toxicity. They are promising platforms for theranostic applications. ${ }^{1-3}$ Previously, in vitro studies of MSNs demonstrated that these materials can be used as drug delivery and cell marking agents. ${ }^{4-6}$ However, it was observed that the bare silica surface (containing reactive silanol groups) can cause aggregation of particles and opsonization in a biological environment, and nonspecifically interact with the membrane of several cell types, which results in poor biocompatibility and pharmacokinetics for in vivo applications..$^{711}$ Modification of the reactive MSN surface with polymers ${ }^{12-15}$ (e.g. PEG and zwitterionic copolymers), small molecules ${ }^{\mathbf{1 0} 16}$ (e.g. phosphonate) or biomolecules ${ }^{17-19}$ (e.g. antibodies, peptides, lipid bilayers, DNA and aptamers) has been proved to be an effective way to improve the biocompatibility of particles as well as the efficiency of MSN based therapies. In particular, short peptide chains have attracted a great deal of attention in recent years because of their tunable functionality, biodegradability, and relative ease of synthesis. ${ }^{20-22}$ It has been shown that short peptide sequences (e.g. RGD and IL-13) can be used for targeting nanoparticles to specific cancer cell lines. ${ }^{22-26}$ In addition to

\footnotetext{
${ }^{a}$ National Nanotechnology Research Center (UNAM), Bilkent University, 06800 Ankara, Turkey.E-mail: moguler@unam.bilkent.edu.tr; atekinay@unam.bilkent.edu.tr; Fax: +90 312266 4365; Tel: +90 3122903552

${ }^{b}$ Institute of Materials Science and Nanotechnology, Bilkent University, 06800 Ankara, Turkey.E-mail: ademy@bilkent.edu.tr

$\dagger$ Electronic supplementary information (ESI) available. See DOI: 10.1039/c4tb00037d

\$ These authors contributed equally.
}

targeting properties, some peptide sequences (e.g. TAT peptide) demonstrated cell penetrating and endosomal escape properties. $^{27-29}$ Also, the biodegradability of peptides makes them suitable for being utilized as stimuli responsive gatekeepers in controlled drug release $\mathrm{e}^{\mathbf{3 0 , 3 1}}$ and linkers in FRET based diagnostics. $^{32-34}$

Conventionally, peptides are covalently attached to the silica surface by using additional cross-linking reagents and troublesome synthetic methods, which results in poor surface grafting density and costly synthesis of functionalized materials. ${ }^{24,30,35}$ In this work, we demonstrate a simple and cost-effective self-assembly approach to prepare peptide functionalized MSNs, as a promising alternative for covalent attachment methods. ${ }^{13}$ Our method is based on the spontaneous attachment of peptide amphiphiles (PAs) to the octyl modified MSN surfaces in aqueous media through hydrophobic interactions between octyl groups of MSNs and alkyl chains of PAs (Scheme 1a). We selected two model PA molecules, with different charges, to functionalize MSNs. The glutamic acid and lysine residues on the PAs provide negative and positive charges to the hybrid system, respectively (Scheme 1b). The unmodified MSNs were synthesized in order to compare with peptide functionalized MSNs. The effect of peptide functionalization on cell viability and uptake was investigated by using human umbilical vein endothelial cells (HUVECs) and a vascular smooth muscle cell line (A10). All of the MSN systems demonstrated good cyto-compatibility with both cell lines up to a concentration of $200 \mu \mathrm{g} \mathrm{mL} \mathrm{mL}^{-1}$. Interestingly, we observed a remarkable increase (1.8 to 6.3 fold) in the cellular uptake of peptide functionalized MSNs compared to bare MSNs depending on the surface charge of PAs as well as the cell type. 
(a)

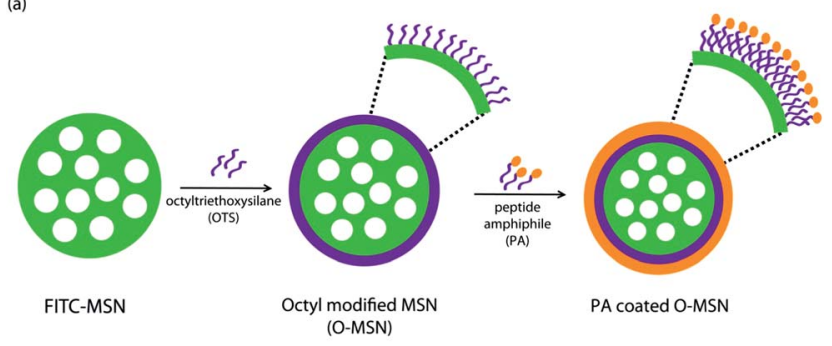

(b)

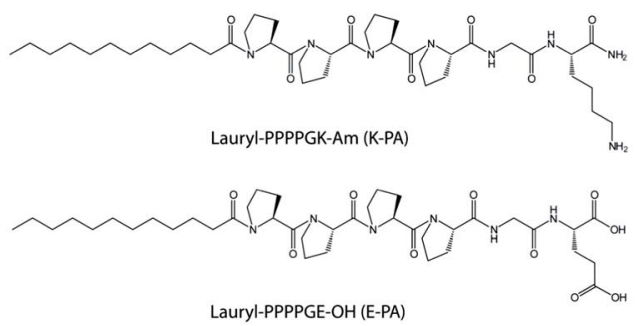

Scheme 1 (a) Schematic presentation of the preparation of peptide functionalized MSNs. (b) Chemical structures of the peptide amphiphile molecules used in this study.

\section{Experimental section}

\section{Materials}

9-Fluorenylmethoxycarbonyl (Fmoc) and tert-butoxycarbonyl (Boc) protected L-amino acids, [4-[ $\alpha-\left(2^{\prime}, 4^{\prime}\right.$-dimethoxyphenyl $)$ Fmocaminomethyl]phenoxy]acetamidonorleucyl-MBHA resin (Rink amide MBHA resin), and 2-(1H-Benzotriazol-1-yl)-1,1,3,3 tetramethyluronium hexafluorophosphate (HBTU) were purchased from NovaBiochem and ABCR. Tetraethyl orthosilicate (TEOS), octyltriethoxysilane (OTS), aminopropyl triethoxysilane (APTES), sodium hydroxide, and lauric acid were purchased from Merck. Fluorescein isothiocyanate (FITC), cetyltriammoniumbromide (CTAB) and ethanol were purchased from Sigma-Aldrich. Methanol was purchased from Carlo-Erba. Tetrahydrofuran (THF) was purchased from Labkim. All reagents and solvents were used as provided. Cell culture chemicals were purchased from Gibco, Life Technologies.

\section{Synthesis of MSNs and OMSNs}

In order to synthesize FITC labelled OMSNs, $2 \mathrm{mg}$ of FITC was conjugated to $10 \mu \mathrm{L}$ of APTES in $1 \mathrm{~mL}$ of ethanol by gently stirring for $24 \mathrm{~h}$. Then, $200 \mathrm{mg}$ of CTAB and $6 \mathrm{mg}$ of $\mathrm{F} 127$ were dissolved in $96 \mathrm{~mL}$ of deionized water and $0.7 \mathrm{~mL}$ of $2 \mathrm{M} \mathrm{NaOH}$ was added. The solution was heated to $80{ }^{\circ} \mathrm{C}$ under vigorous stirring $(600 \mathrm{rpm})$. After the temperature of the reaction mixture was stabilized at $80{ }^{\circ} \mathrm{C}, 1 \mathrm{~mL}$ of TEOS and FITC solution was rapidly added. After $75 \mathrm{~min}, 0.2 \mathrm{~mL}$ of OTS was dissolved in $10 \mathrm{~mL}$ THF and slowly added to the reaction mixture in order to form an octyl-containing shell. The mixture was further stirred for $90 \mathrm{~min}$. Finally, the particles were collected by centrifugation at $9000 \mathrm{rpm}$ and washed with methanol twice. Surfactant extraction was performed by stirring the particles in $50 \mathrm{~mL}$ of $20 \mathrm{~g} \mathrm{~L}^{-1}$ ethanolic ammonium nitrate at $60{ }^{\circ} \mathrm{C}$ for $1 \mathrm{~h}$. This treatment was repeated twice to ensure complete surfactant removal. Particles were washed with ethanol twice and dried at $50{ }^{\circ} \mathrm{C}$ overnight. MSNs were synthesized by using the same parameters with the exception of OTS addition.

\section{Synthesis and characterization of peptide amphiphile molecules}

The positively charged peptide amphiphile (K-PA) was constructed on MHBA Rink Amide $\left(0.59 \mathrm{mmol} \mathrm{g}^{-1}\right.$ loading) resin, and the negatively charged peptide amphiphile (E-PA) was constructed on Fmoc-Glu-Wang $\left(0.64 \mathrm{mmol} \mathrm{g}^{-1}\right.$ loading) resin. All amino acid couplings were performed with 2 equivalents of Fmoc protected amino acid, 1.95 equivalents of HBTU and 3 equivalents of $\mathrm{N}, \mathrm{N}$-diisopropylethylamine (DIEA) in dimethylformamide (DMF) for $2 \mathrm{~h}$. Fmoc removals were performed with $20 \%$ piperidine-DMF solution for $20 \mathrm{~min}$. The cleavage of the peptides from the resin was carried out with a mixture of trifluoroacetic acid (TFA)-triisopropylsilane (TIS)-water in the ratio of $95: 2.5: 2.5$ for $2 \mathrm{~h}$. Excess TFA was removed by rotary evaporation. The remaining viscous peptide solution was treated with ice-cold diethyl ether and the resulting white pellet was freezedried. The peptide amphiphiles were identified and analyzed by reverse phase HPLC on an Agilent 6530 accurate-Mass Q-TOF LC/ MS equipped with an Agilent 1200 HPLC. A phenomenex Luna $3 \mu$ C8 $100 \mathrm{~A}(50 \times 3.00 \mathrm{~mm})$ column as the stationary phase and water-acetonitrile gradient with $0.1 \%$ volume of formic acid as the mobile phase were used to identify the positively charged peptide amphiphile. For the negatively charged peptide amphiphile, an Agilent Zorbax Extend-C18 $(2.1 \times 50 \mathrm{~mm})$ column as the stationary phase and water-acetonitrile gradient with $0.1 \%$ volume of ammonium hydroxide as the mobile phase were used. The positively and negatively charged peptide amphiphiles were purified by using a 1200 Agilent HPLC on a Zorbax 300SB C8 (21.2 $\times 150 \mathrm{~mm})$ PrepHT and a Zorbax-Extend C18 $(21.2 \times 150 \mathrm{~mm})$ PrepHT column, respectively.

\section{Coating the OMSN with peptide amphiphiles}

While $14 \mathrm{mg}$ of each peptide amphiphile was sonicated in 12 $\mathrm{mL}$ deionized water, $2 \mathrm{mg}$ of OMSNs was slowly added to the system. Peptide amphiphiles and OMSNs were mixed in a weight ratio of $1: 7$. They were sonicated and vortexed for $3 \mathrm{~h}$ at room temperature. The solution was centrifuged at $5000 \mathrm{rpm}$. After all portions were concentrated by centrifugation, they were rinsed with water and centrifuged twice.

\section{Characterization of the particles}

The hydrodynamic size and zeta potential of the particles were measured by using a Zetasizer. A Malvern Nanosizer/Zetasizer nano-ZS ZEN 3600 (Malvern Instruments, USA) instrument was used for the analysis. Measurements were performed in glass cuvettes and repeated at least three times. TEM images were obtained using a FEI Tecnai G2 F30 TEM at $300 \mathrm{kV}$. Samples for imaging were prepared by diluting PA coated MSNs to $0.01 \%(\mathrm{w} / \mathrm{v})$ on a 200-mesh copper TEM grid for $5 \mathrm{~min}$ without staining and air dried. Fluorescence spectra of the particles were recorded using a Varian Eclipse spectrophotometer with an excitation wavelength of $488 \mathrm{~nm}$. FTIR spectra of particles and PAs were collected by 
using an FTIR spectrometer (Vertex 70, Bruker). Thermogravimetric analyses (TGA) were performed with a Q500 (TA Instruments). The temperature was increased from room temperature to $800{ }^{\circ} \mathrm{C}$ with a rate of $20{ }^{\circ} \mathrm{C} \mathrm{min}^{-1}$ under nitrogen gas.

\section{Cell culture experiments}

Viability and uptake experiments were performed by using human umbilical vein endothelial cells (HUVECs) and A10 rat aortic smooth muscle cells (ATCC® Cat\# CRL-1476 ${ }^{\mathrm{TM}}$ ). HUVECs were donated by Yeditepe University, Istanbul, Turkey. HUVECs were purified as described ${ }^{36}$ and characterized by staining with CD34, CD31, and CD90 surface markers. These cells were found to be positive for CD31 and CD34 but negative for CD90. A10 and HUVEC cells were cultured in $75 \mathrm{~cm}^{2}$ polystyrene cell culture flasks with standard medium, containing Dulbecco's modified eagle medium (DMEM) with 10\% fetal bovine serum (FBS), and $1 \%$ penicillin-streptomycin and passaged at cell confluency between 80 and $90 \%$ using trypsin-EDTA. In all experiments, particles were administered in serum free medium (1\% penicillin-streptomycin containing DMEM) to avoid any influence of serum proteins on the uptake mechanism.

\section{Cell viability tests}

The cell viability assay was performed using Alamar Blue Assay (Invitrogen). 5000 cells per well (HUVECs or A10) were seeded on a 96-well plate in $100 \mu \mathrm{L}$ of standard medium. After $24 \mathrm{~h}$, the medium was removed and $100 \mu \mathrm{L}$ of serum free medium was added. $25 \mu \mathrm{L}$ of freshly prepared nanoparticle solutions in water at different concentrations were administered to have final concentrations of $200,100,50$, and $10 \mu \mathrm{g} \mathrm{mL}{ }^{-1}$. For cell viability tests, cells were exposed to particles for $4 \mathrm{~h}$, then the medium was changed to standard medium and the cells were further incubated for $20 \mathrm{~h}$. Then, Alamar Blue reagent diluted to $10 \%$ in DMEM was added. After $3 \mathrm{~h}$, fluorescence at 570/612 nm (Ex/ Em) was measured using a microplate reader (SpectraMax, M5).

\section{Cellular uptake analyses}

$13 \mathrm{~mm}$ glass coverslips were placed in 24-well plates and $4 \times 10^{4}$ cells (HUVECs or A10) in standard medium were seeded in each well. After $24 \mathrm{~h}$, the medium was discarded, and $400 \mu \mathrm{L}$ of serum free medium was added to each well. $100 \mu \mathrm{L}$ of bare or functionalized MSNs were administered to have a final concentration of $200 \mu \mathrm{g} \mathrm{mL}^{-1} \mathrm{MSNs}$. After $4 \mathrm{~h}$, the medium was exchanged to standard medium. After $20 \mathrm{~h}$, the cells were washed with PBS several times and fixed with $4 \%$ paraformaldehyde for $15 \mathrm{~min}$. Then, the cells were permeabilized with $0.1 \%$ TritonX-100 (Sigma-Aldrich) for $12 \mathrm{~min}$ and actin proteins were stained with Phalloidin-TRITC (Sigma-Aldrich) for $20 \mathrm{~min}$. Coverslips were mounted on slides with Antifade (Invitrogen). Samples were visualized with a laser scanning confocal microscope (Zeiss, LSM 510).

\section{Flow cytometry analysis}

$1 \times 10^{5}$ HUVECs or A10 cells per well were seeded in 6 well plates in standard medium. The medium was discarded after

$24 \mathrm{~h}$ and $1600 \mu \mathrm{L}$ of serum free medium was added to each well. $400 \mu \mathrm{L}$ of bare or functionalized MSNs were administered to have a final concentration of $200 \mu \mathrm{g} \mathrm{mL}^{-1}$ MSNs. After $4 \mathrm{~h}$, the medium was changed to standard medium and the cells were incubated for $20 \mathrm{~h}$, then washed with PBS and trypsinized. The cells were collected by centrifugation, washed twice with PBS, resuspended in $1 \mathrm{~mL}$ PBS and kept on ice before analysis. An FITC channel was used to analyze the MSN uptake using a flow cytometer (BD, FACS Aria III). Non-treated cells were used as the control. Student's $t$-test was applied to all datasets and a $p$ value of less than 0.05 was accepted to be statistically significant.

\section{Results and discussion}

\section{Synthesis and characterization of peptide functionalized MSNs}

Octyl modified water insoluble MSNs (OMSNs) were synthesized according to our previous reports ${ }^{13,37}$ by using a one-pot respective condensation method. ${ }^{38}$ Tetraethyl orthosilicate (TEOS) molecules were condensed under basic conditions and initial MSNs were formed. Then, octyl triethoxysilane (OTS) molecules were added to the reaction mixture to coat the MSNs with a hydrophobic octyl layer. The fluorescein isothiocyanate (FITC) molecules were conjugated to the MSNs in the first step of the synthesis to track the uptake of particles by using confocal imaging and flow cytometry methods. ${ }^{16}$ Successful conjugation of FITC to the silica network was demonstrated by using fluorescence spectroscopy, where emission bands of FITC molecules were clearly observed (ESI, $\dagger$ Fig. S1). Bare MSNs were prepared for control experiments under the same experimental conditions without the OTS addition. Peptide amphiphiles were synthesized by solid phase peptide synthesis method based on orthogonal protection and verified by liquid chromatography and mass spectrometry (ESI, $\dagger$ Fig. S2 and S3).

OMSNs were coated with peptide amphiphile molecules by simple sonication in E-PA or K-PA solutions (Fig. 1a). Asprepared OMSNs are insoluble in water (Fig. 1a, left) because their surface is covered with hydrophobic octyl groups. After the addition of PA solution and ultrasonication, PA molecules selfassemble on the OMSNs due to hydrophobic interactions between alkyl chains of both OMSNs and PAs (Scheme 1a). Functionalization with peptide amphiphiles renders the MSNs

(a)

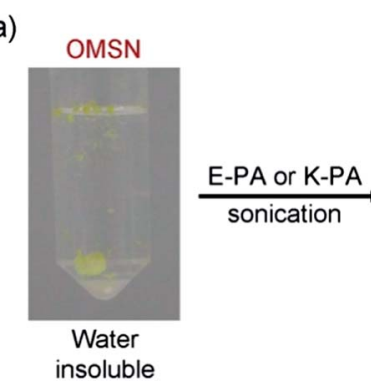

Fig. 1 (a) Photograph showing the water dispersion of OMSNs before and after coating with peptide amphiphiles and (b) photographs of MSN dispersion in water. 
water dispersible by providing either positively or negatively charged water soluble moieties on their surfaces. Photographs of MSNs dispersed in water are shown in Fig. 1b. Both dispersions have light green color due to the covalently conjugated FITC molecules. Fig. 2 shows the TEM images of the particles. Bare MSNs exhibited an MCM-41 type highly ordered hexagonal porous structure (Fig. 2a). On the other hand, for OMSNs, a randomly porous thin shell was observed over an MCM-41 type porous core (Fig. 2 b) which is in accordance with our previous work. ${ }^{13}$ After coating the OMSNs with E-PAs, a thin organic layer was observed around the particles (Fig. 2c). In addition, a TEM image of K-PA peptide coated OMSNs is provided in the ESI $\dagger$ (Fig. S4).

The formation of a peptide coating over OMSNs was further proved by using FTIR and TGA methods. Fig. 3a shows the FTIR spectra of the particles. The -CH peaks between $2800 \mathrm{~cm}^{-1}$ and $3000 \mathrm{~cm}^{-1}$ were observed in the spectrum of OMSNs indicating the successful octyl modification. These absorption bands became stronger for PA modified particles (E-OMSNs and K-OMSNs) due to the $-\mathrm{CH}$ bonds of the PAs. In addition, new absorption bands between $1400 \mathrm{~cm}^{-1}$ and $1800 \mathrm{~cm}^{-1}$ appeared, which are in good agreement with FTIR spectra of the PAs. The amide I (1600-1690 $\mathrm{cm}^{-1}, \mathrm{C}=\mathrm{O}$ stretching) and amide II (1480$1575 \mathrm{~cm}^{-1}$, CN stretching, $\mathrm{NH}$ bending) bands of PAs were observed for PA functionalized MSNs. Another $\mathrm{C}=\mathrm{O}$ stretching vibration was also observed for glutamic acid containing particles at around $1725 \mathrm{~cm}^{-1}$ which corresponds to the side chain of the glutamic acid.

Fig. $3 \mathrm{~b}$ shows the TGA analysis of the particles. For MSNs, a small weight loss of $7.8 \%$ was observed between $100{ }^{\circ} \mathrm{C}$ and $800{ }^{\circ} \mathrm{C}$ due to the dehydroxylation of the silica surface. ${ }^{39}$ The weight loss increased to $11.9 \%$ for OMSNs and most of the weight loss occurred at around $500{ }^{\circ} \mathrm{C}$ indicating the decomposition of octyl moieties. ${ }^{13}$ For E-OMSNs and K-OMSNs large weight loss values of $19.6 \%$ and $32.5 \%$ were recorded, respectively. Also, two sharp decreases were observed in the spectra of peptide coated particles around $400{ }^{\circ} \mathrm{C}$ and $500{ }^{\circ} \mathrm{C}$, which correspond to the decomposition of PAs and octyl groups, respectively. For bare peptide amphiphiles, almost all weight was lost at $800{ }^{\circ} \mathrm{C}$. Based on the TGA results, we calculated grafting densities of the PA molecules on the OMSN surfaces (see ESI $\dagger$ for details). ${ }^{40,41}$ The grafting densities of E-OMSNs and K-OMSNs were 0.94 and $2.95 \mathrm{PA} \mathrm{nm}^{-2}$, respectively, indicating that the surface of OMSNs was densely covered by the peptide molecules. A higher grafting density of K-OMSNs was observed due to the electrostatic interactions between positively charged

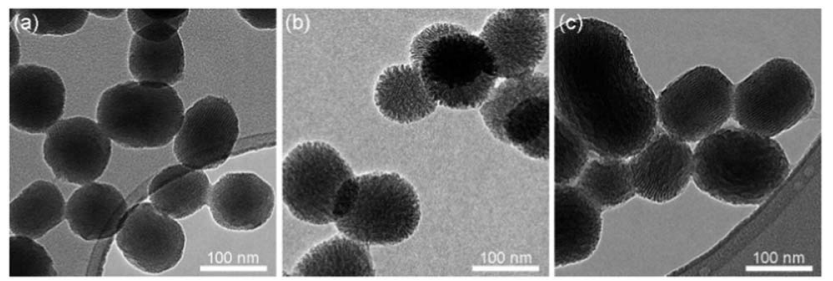

Fig. 2 Characterization of the mesoporous silica nanoparticles. TEM images of (a) MSNs, (b) OMSNs and (c) E-OMSNs.
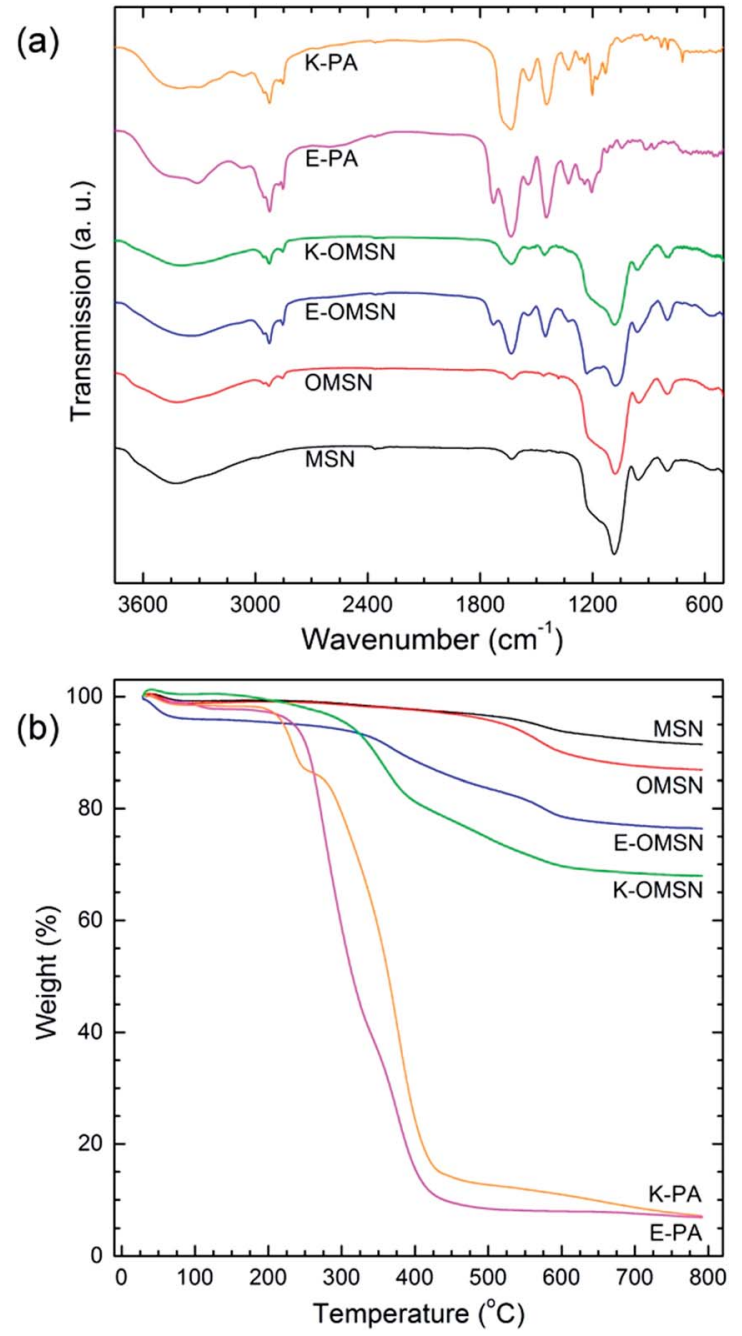

Fig. 3 FTIR spectra (a) and TGA spectra (b) of particles and peptide amphiphiles, respectively.

K-PAs and unreacted surface silanol groups of OMSNs. Particle sizes of the MSNs and OMSNs were calculated to be $100 \mathrm{~nm}$ and $104 \mathrm{~nm}$, respectively from the TEM images (Table 1). The $4 \mathrm{~nm}$ increase in the particle size after octyl addition shows the $\sim 2$ $\mathrm{nm}$ shell formation around the particles. Hydrodynamic sizes of the MSN, E-MSN and K-MSN were measured by using the dynamic light scattering technique (Table 1 and ESI, $\uparrow$ Fig. S5).

The OMSNs are water insoluble and it is not possible to measure their hydrodynamic size. Hydrodynamic sizes of the peptide coated particles are slightly larger (around $40 \mathrm{~nm}$ ) than their primary particle sizes (size of OMSNs) due to the slight

Table 1 Physical properties of bare, octyl modified and peptide functionalized MSNs

\begin{tabular}{llll}
\hline Sample & TEM size $(\mathrm{nm})$ & DLS size $(\mathrm{nm})$ & Zeta potential $(\mathrm{mV})$ \\
\hline MSNs & $99.8 \pm 20.7$ & $166.5 \pm 8.0$ & $-36.6 \pm 1.1$ \\
OMSNs & $104.3 \pm 21.5$ & N/A & N/A \\
E-OMSNs & N/A & $143.8 \pm 19.8$ & $-38.0 \pm 0.8$ \\
K-OMSNs & N/A & $145.2 \pm 1.6$ & $-25.1 \pm 0.7$
\end{tabular}


aggregation in aqueous media for these particles. On the other hand, aggregation becomes more pronounced for bare MSNs with a $67 \mathrm{~nm}$ difference between hydrodynamic and primary particle sizes. This difference could be explained by the fact that two different techniques, TEM and DLS, were used for the measurements. While dried samples were used for TEM imaging, the hydrodynamic size of particles was measured using DLS where interactions with solvent molecules are also taken into account. The surfaces of the particles were characterized by measuring their zeta potentials (Table 1 ). The bare MSN surface is negatively charged $(-37 \mathrm{mV})$ due to the surface silanol groups. ${ }^{\mathbf{1 0}}$ Modifying the MSN surface with a negatively charged E-PA did not significantly affect the zeta potential of the surface $(-38 \mathrm{mV})$ since both silanol and E-PA groups are negatively charged. Coating the MSN surface with a positively charged K-PA, on the other hand, resulted in a remarkable increase in the zeta potential $(-25 \mathrm{mV})$.

\section{Cyto-compatibility of MSNs}

A good compatibility of therapeutic nanoparticles with biological organisms is necessary to prevent possible side effects of
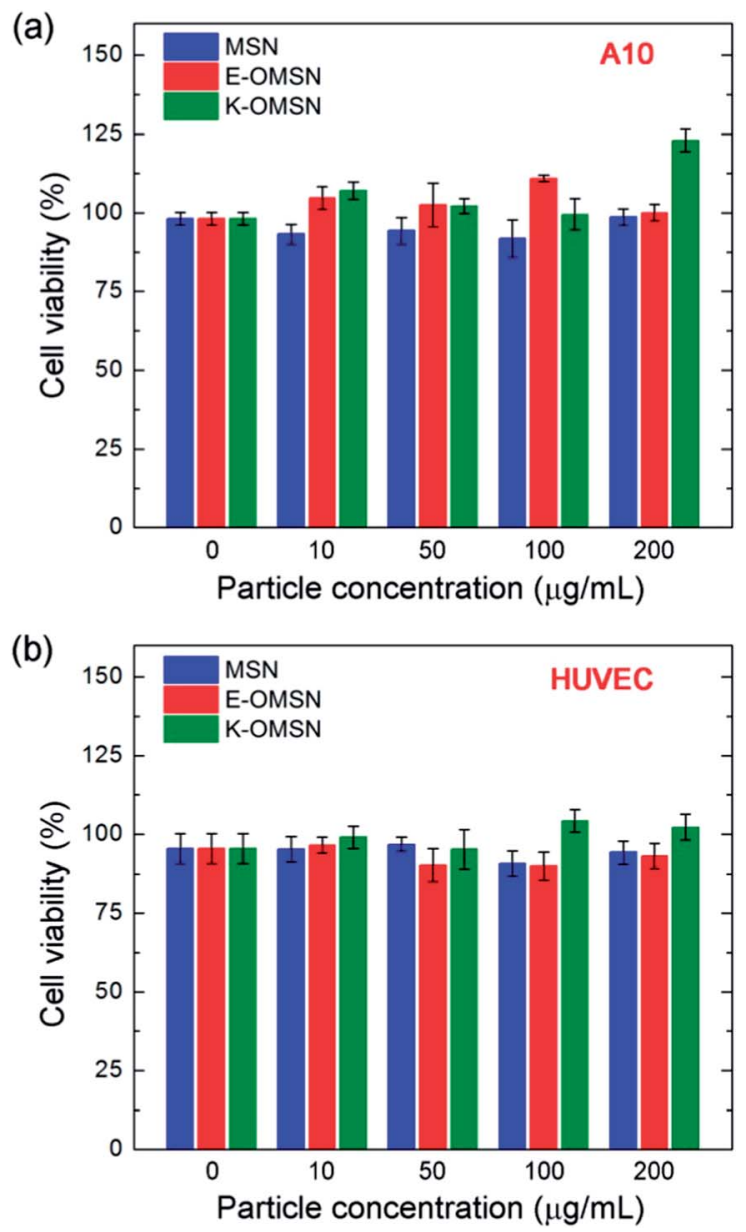

Fig. 4 Cytotoxicity results of bare and peptide functionalized MSNs. (a) A10 cells incubated for $4 \mathrm{~h}$ with particles and $20 \mathrm{~h}$ in particle free media and (b) HUVEC cells incubated for $4 \mathrm{~h}$ with particles and $20 \mathrm{~h}$ in particle free media. these therapies. Accordingly, the in vitro cytocompatibilities of the peptide coated and bare MSNs were evaluated by using HUVEC and A10 cell lines. The viability of the cells treated with different particle concentrations (10 to $200 \mu \mathrm{g} \mathrm{mL} \mathrm{m}^{-1}$ ) was studied by using the Alamar blue assay. First, cells were treated with particles for $4 \mathrm{~h}$ and then incubated for additional $20 \mathrm{~h}$ in particle free media. None of the particles showed decrease in the viability of both cell lines even at a very high particle concentration of $200 \mu \mathrm{g} \mathrm{mL} \mathrm{m}^{-1}$ (Fig. $4 \mathrm{a}$ and b).

\section{Cellular uptake studies}

Improving the cellular uptake of the therapeutic nanoparticles is essential for enhancing their efficacy. Therefore, we studied the uptake of the particles by A10 cells and HUVEC by using confocal microscopy and flow cytometry techniques. Both A10 cells and HUVEC were treated with $200 \mu \mathrm{g} \mathrm{mL}{ }^{-1}$ nanoparticles for $4 \mathrm{~h}$ and the cells were analyzed after $20 \mathrm{~h}$ of further incubation. As shown in Fig. 5, confocal microscopy revealed that the peptide coated particles were internalized remarkably more than the bare MSNs by both cell lines.

In order to compare the uptake amount of the particles, the fluorescence of the internalized particles was quantified by using a flow cytometer (Fig. 6). More uptake was observed for K-OMSNs in both cell lines. The amount of internalized fluorescent E-OMSNs was less than that of K-OMSNs, however, they were internalized more than bare particles. The uptake of K-OMSNs by A10 cells and HUVEC was 2.3 and 6.3 fold larger than the uptake of MSNs, respectively. Also, E-OMSNs demonstrated 1.8 and 3.1 fold increased uptake by A10 cells and

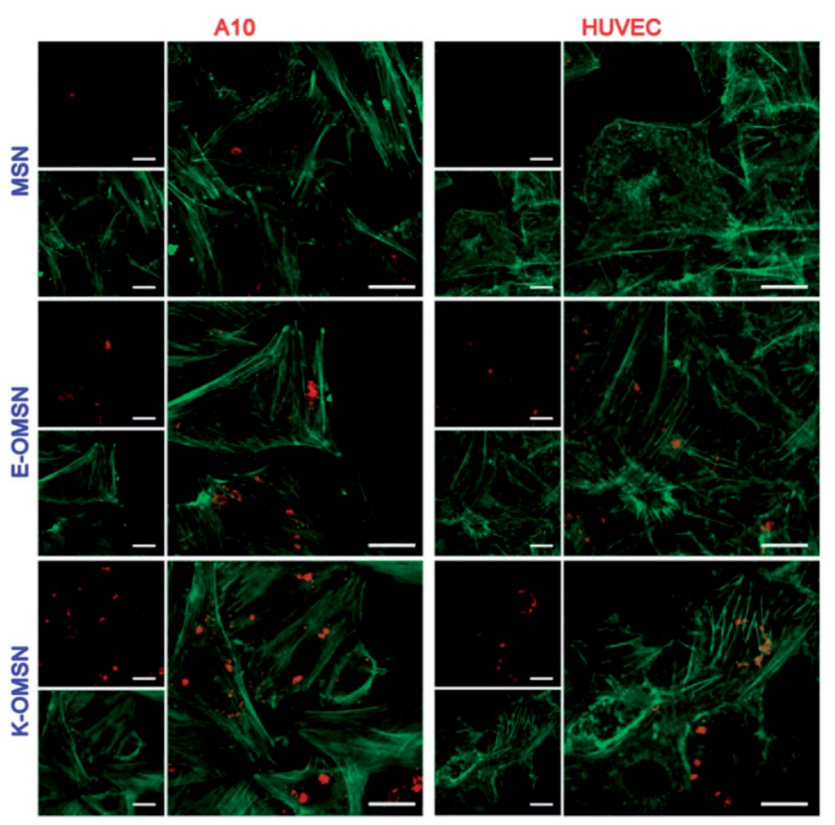

Fig. 5 Uptake results of bare and peptide functionalized MSNs. Confocal results showing that peptide functionalized particles were internalized more both A10 and HUVEC cell lines. Upper images at left show the fluorescence of particles, lower images at left show the fluorescence of actin filaments stained by Phalloidin-TRITC and panels on right show the merged images. 

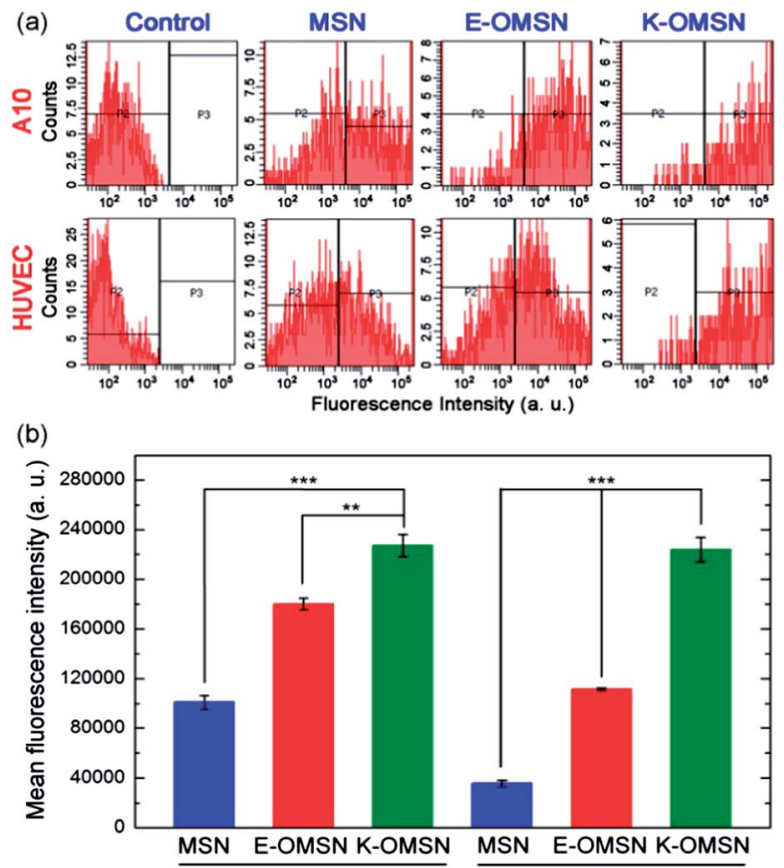

Fig. 6 Flow cytometry analysis of A10 cells and HUVECs treated with bare and peptide functionalized MSNs. (a) Flow cytometry histograms. (b) Graph demonstrates the improved uptake of peptide functionalized MSNs. Data were generated from at least three independent experiments. According to Student's t-test, ${ }^{* *} p<0.001$ and ${ }^{* * *} p<0.0001$.

HUVEC, respectively, compared to bare MSNs. It is well known that positively charged surfaces can electrostatically interact with the slightly negatively charged cell membrane. ${ }^{42}$ Therefore, the highest cellular internalization was observed for positively charged K-PA functionalized K-OMSNs. Although, both MSN and E-OMSN samples have about the same zeta potential values, around $-40 \mathrm{mV}$, the cellular uptake of E-OMSNs was significantly higher than that of the MSNs. This observation indicates that the uptake rate and the amount of the nanoparticles cannot be simply correlated with the net surface charge of the surface; instead, it is more related to the chemical structure of the surface functional groups.

\section{Conclusions}

In summary, we developed a straightforward method to functionalize MSNs with short peptide chains by using self-assembly of PAs around the hydrophobic MSNs. The resulting peptide functionalized particles can be easily dispersed in the aqueous media. We observed that peptide functionalized MSNs are not toxic to the A10 cells and HUVEC up to a high dose of $100 \mu \mathrm{g}$ $\mathrm{mL}^{-1}$. In addition, it was observed that the cellular uptake of MSNs can be enhanced up to 6.3 fold by coating them with PAs, especially positively charged ones. We believe that the facile method demonstrated in this study can be applied to prepare MSNs with diverse functionalities including cancer cell targeting, cell penetrating properties and responsive drug release, by simply changing the peptide signal to achieve selective bioactive properties.

\section{Acknowledgements}

M.S., D.M. and A.Y. are supported by TUBITAK-BIDEB fellowships. FACS analyses were performed at Diskapi Yildirim Beyazit Training and Research Hospital, and we thank E. Calisir, Prof. T. Delibasi and ADAcell for help in FACS experiments. M.O.G and A.B.T. acknowledge support from the Turkish Academy of Sciences Distinguished Young Scientist Award (TUBA-GEBIP) and TUBITAK 112T042.

\section{Notes and references}

1 K. T. Mody, A. Popat, D. Mahony, A. S. Cavallaro, C. Yu and N. Mitter, Nanoscale, 2013, 5, 5167-5179.

2 J. E. Lee, N. Lee, T. Kim, J. Kim and T. Hyeon, Acc. Chem. Res., 2011, 44, 893-902.

3 S.-H. Wu, Y. Hung and C.-Y. Mou, Chem. Commun., 2011, 47, 9972-9985.

4 J. Lu, M. Liong, J. I. Zink and F. Tamanoi, Small, 2007, 3, 1341-1346.

5 C. Liu, J. Guo, W. Yang, J. Hu, C. Wang and S. Fu, J. Mater. Chem., 2009, 19, 4764-4770.

6 Y.-S. Lin, C.-P. Tsai, H.-Y. Huang, C.-T. Kuo, Y. Hung, D.-M. Huang, Y.-C. Chen and C.-Y. Mou, Chem. Mater., 2005, 17, 4570-4573.

7 S. Sharifi, S. Behzadi, S. Laurent, M. L. Forrest, P. Stroeve and M. Mahmoudi, Chem. Soc. Rev., 2012, 41, 2323-2343.

8 S. P. Hudson, R. F. Padera, R. Langer and D. S. Kohane, Biomaterials, 2008, 29, 4045-4055.

9 Y. Zhao, X. Sun, G. Zhang, B. G. Trewyn, I. I. Slowing and V. S.-Y. Lin, ACS Nano, 2011, 5, 1366-1375.

10 A. Yildirim, E. Ozgur and M. Bayindir, J. Mater. Chem. B, 2013, 1, 1909-1920.

11 L.-S. Wang, L.-C. Wu, S.-Y. Lu, L.-L. Chang, I.-T. Teng, C.-M. Yang and J.-A. A. Ho, ACS Nano, 2010, 4, 4371-4379.

12 Q. He, J. Zhang, J. Shi, Z. Zhu, L. Zhang, W. Bu, L. Guo and Y. Chen, Biomaterials, 2010, 31, 1085-1092.

13 A. Yildirim, G. B. Demirel, R. Erdem, B. Senturk, T. Tekinay and M. Bayindir, Chem. Commun., 2013, 49, 9782-9784.

14 J. T. Sun, Z. Q. Yu, C. Y. Hong and C. Y. Pan, Macromol. Rapid Commun., 2012, 33, 811-818.

15 M. Ma, H. Chen, Y. Chen, K. Zhang, X. Wang, X. Cui and J. Shi, J. Mater. Chem., 2012, 22, 5615-5621.

16 M. Liong, J. Lu, M. Kovochich, T. Xia, S. G. Ruehm, A. E. Nel, F. Tamanoi and J. I. Zink, ACS Nano, 2008, 2, 889-896.

17 N. Erathodiyil and J. Y. Ying, Acc. Chem. Res., 2011, 44, 925935.

18 M. M. van Schooneveld, E. Vucic, R. Koole, Y. Zhou, J. Stocks, D. P. Cormode, C. Y. Tang, R. E. Gordon, K. Nicolay and A. Meijerink, Nano Lett., 2008, 8, 2517-2525.

19 C. E. Ashley, E. C. Carnes, G. K. Phillips, D. Padilla, P. N. Durfee, P. A. Brown, T. N. Hanna, J. Liu, B. Phillips and M. B. Carter, Nat. Mater., 2011, 10, 389-397.

20 S. Sulek, B. Mammadov, D. I. Mahcicek, H. Sozeri, E. Atalar, A. B. Tekinay and M. O. Guler, J. Mater. Chem., 2011, 21, 15157-15162. 
21 R. M. Levine, C. M. Scott and E. Kokkoli, Soft Matter, 2013, 9, 985-1004.

22 D. P. Ferris, J. Lu, C. Gothard, R. Yanes, C. R. Thomas, J. C. Olsen, J. F. Stoddart, F. Tamanoi and J. I. Zink, Small, 2011, 7, 1816-1826.

23 K. Epler, D. Padilla, G. Phillips, P. Crowder, R. Castillo, D. Wilkinson, B. Wilkinson, C. Burgard, R. Kalinich and J. Townson, Adv. Healthcare Mater., 2012, 1, 348-353.

24 S.-H. Cheng, C.-H. Lee, M.-C. Chen, J. S. Souris, F.-G. Tseng, C.-S. Yang, C.-Y. Mou, C.-T. Chen and L.-W. Lo, J. Mater. Chem., 2010, 20, 6149-6157.

25 Y. Wang, W. Shi, W. Song, L. Wang, X. Liu, J. Chen and R. Huang, J. Mater. Chem., 2012, 22, 14608-14616.

26 L. Pan, Q. He, J. Liu, Y. Chen, M. Ma, L. Zhang and J. Shi, J. Am. Chem. Soc., 2012, 134, 5722-5725.

27 X. Li, Y. Chen, M. Wang, Y. Ma, W. Xia and H. Gu, Biomaterials, 2013, 34, 1391-1401.

28 I. L. Medintz, T. Pons, J. B. Delehanty, K. Susumu, F. M. Brunel, P. E. Dawson and H. Mattoussi, Bioconjugate Chem., 2008, 19, 1785-1795.

29 S.-F. Ye, M.-M. Tian, T.-X. Wang, L. Ren, D. Wang, L.-H. Shen and T. Shang, J. Nanomed. Nanotechnol., 2012, 8, 833-841.

30 C. Coll, L. Mondragón, R. Martínez-Máñez, F. Sancenón, M. D. Marcos, J. Soto, P. Amorós and E. Pérez-Payá, Angew. Chem., Int. Ed., 2011, 50, 2138-2140.
31 G.-F. Luo, W.-H. Chen, Y. Liu, J. Zhang, S.-X. Cheng, R.-X. Zhuo and X.-Z. Zhang, J. Mater. Chem. B, 2013, 1, 5723-5732.

32 M. Oishi, A. Tamura, T. Nakamura and Y. Nagasaki, Adv. Funct. Mater., 2009, 19, 827-834.

33 Y. Choi, Y. Cho, M. Kim, R. Grailhe and R. Song, Anal. Chem., 2012, 84, 8595-8601.

34 D. Deng, D. Zhang, Y. Li, S. Achilefu and Y. Gu, Biosens. Bioelectron., 2013, 49, 216-221.

35 I. M. Rio-Echevarria, R. Tavano, V. Causin, E. Papini, F. Mancin and A. Moretto, J. Am. Chem. Soc., 2010, 133, 8-11.

36 B. Baudin, A. Bruneel, N. Bosselut and M. Vaubourdolle, Nat. Protoc., 2007, 2, 481-485.

37 A. Yildirim, H. Budunoglu, B. Daglar, H. Deniz and M. Bayindir, ACS Appl. Mater. Interfaces, 2011, 3, 1804-1808. 38 V. Cauda, A. Schlossbauer, J. Kecht, A. Zürner and T. Bein, J. Am. Chem. Soc., 2009, 131, 11361-11370.

39 L. Zhuravlev, Langmuir, 1987, 3, 316-318.

40 M. Kar, P. Vijayakumar, B. Prasad and S. S. Gupta, Langmuir, 2010, 26, 5772-5781.

41 D. Kim, S. Finkenstaedt-Quinn, K. R. Hurley, J. T. Buchman and C. L. Haynes, Analyst, 2014, 139, 906-913.

42 L. Chen, J. M. Mccrate, J. C. Lee and H. Li, Nanotechnology, 2011, 22, 105708. 